\title{
What is the best way to tell when your two minutes are up? A randomized trial of telling time in Basic Life Support cycles of two minutes
}

\author{
Lars Folkestad*, Hans-Christian Pommergaard, Fredrik Mondrup, Mikkel Brabrand \\ From Danish Society for Emergency Medicine: Research Symposium 2010 \\ Roskilde, Denmark. 20-21 May 2010
}

\section{Background}

The current resuscitation guidelines state that basic life support (BLS) should be conducted in two minute cycles. This regime dictates the frequencies of medicine administration and defibrillation during advanced life support in cardiac arrests. Earlier work has shown that participants in a cardiac arrest teams lose their time perception and both over- and underestimate elapsed time. We therefore investigated the best way to tell time during BLS.

\section{Methods}

We randomized how the participants should tell time during a BLS cycle. Two methods had an auditory alarm (a person telling the participant when two minutes had elapsed and an alarm-clock going off after two minutes). Six methods made the participant use silent ways to tell time, such as using a large digital watch displayed on the wall, the clock on defibrillator, counting out compression and ventilation cycles (5 alterations) or by counting the total number of compressions (200 compressions). We calculated the sample size to be 9 in each group (power 0.8, alfa 0.05, mean 120 seconds (SD 1.0) vs. 115 seconds (SD 5.0)). We will here present data comparing the median time spent on one cycle from the group that was given auditory alarm (AA-group) to the median time using all other methods (AOM-group). Seeing that the data were nonparametric, we used Wilcoxon signed-rank test.

\section{Results}

16 physicians participated in the study (6 male, mean age 29 years, median number of participation in cardiac

* Correspondence: larsfolkestad@surfmail.dk

Medical Admission Unit, Sydvestjysk Sygehus Esbjerg, Esbjerg, Denmark arrests 7.5 [range 0-150]). There were 10 BLS sessions in the AA group and 22 in the AOM group. When using an auditory alarm the median time spent on one cycle was 121.9 [range 120.4-123.1] seconds. When using all other methods to tell time the median time spent on one cycle was 110.5 [range 71.7-172.7] seconds, $\mathrm{p}=0.005$.

\section{Conclusion}

We conclude that in order to follow the guidelines of two minutes of BLS you need an auditory alarm to tell you when your two minutes are up, either by a person telling you or an alarm that sounds every two minutes.

Published: 17 September 2010

doi:10.1186/1757-7241-18-S1-P41

Cite this article as: Folkestad et al:: What is the best way to tell when your two minutes are up? A randomized trial of telling time in Basic Life Support cycles of two minutes. Scandinavian Journal of Trauma, Resuscitation and Emergency Medicine 2010 18(Suppl 1):P41.

Submit your next manuscript to BioMed Central and take full advantage of:

- Convenient online submission

- Thorough peer review

- No space constraints or color figure charges

- Immediate publication on acceptance

- Inclusion in PubMed, CAS, Scopus and Google Scholar

- Research which is freely available for redistribution

Submit your manuscript at www.biomedcentral.com/submit
Biomed Central 